Health \& Medicine | Abhishek K. Kala, Sam Atkinson \& Chetan Tiwari

\section{Geovisualization for insights into infectious disease risk}

used to explore relationships between the outcome and potential explanatoy development efforts.

Dr Kala, Dr Atkinson and Dr Tiwari have many years of experience in studying disease transmission. They are perticulaly interested in spatial epidemiology- analyzing the geographic distribution of disease risk and corresponding impacts on health outcomes. Recently they have begun to consider demographic characteristics in addition to the environmental context. Considering many factors together poses significant challenges given large volumes of potentially unstructured and unrelated datasets. Additionally, many of these factors will interact together, and the dat may have been collected over different scales (for example, by county or by to combine It is possible to use complex models to analyze these factors and their interactions, but the research tean suggests that geovisualization techniques could help identify the most relevant factors as a basis for creating more usefu and predictive models.

\section{GEOVISUALIZATION}

Geovisualization is the use of tools and techniques to support the analysis of

large amounts of geospatial data through the use of interactive visualization. It is essentially a data mining process, and is commonly used to identity the spatial context and associated relationships between a pre-defined setor potential explanatory variables. The research
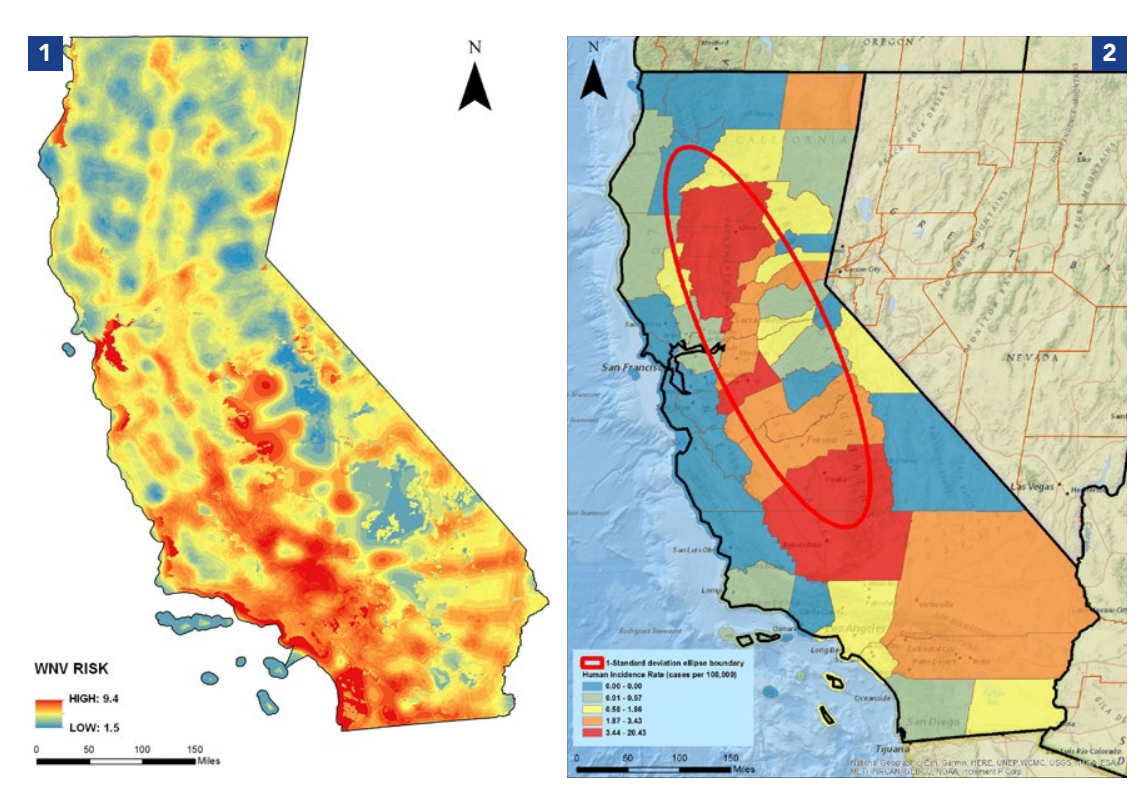

1 - West Nile Virus (WNV) risk
based on environmental context
modelling (i.e., mosquito habitat

2- West Nile Virus human incidence rate by county in California. Co
represent quintiles of reported
human incidence of WNV.

- Self organising map epresenting 49 nodes (circles) with combination of contextual compositional param
1,133 census tracts.

techniques: self-organising maps (SOM), parallel coordinate plots (PCP) and geographic mapping

A self-organising map (SOM) is a Austering method of data visualization. of the sudy area (eg neighoctions (c)

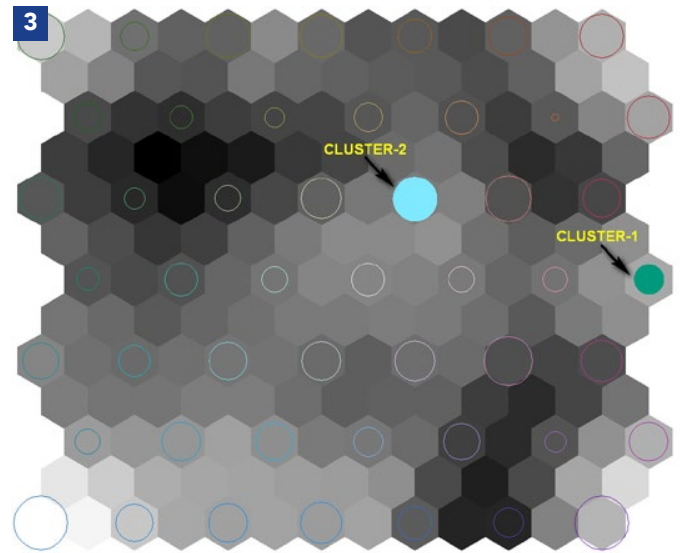

represented as a line graph with multiple vertical axes, one for each of the factors included in the analysis. All of the clusters are represented by a line on the graph, there are 30 lines on the $\mathrm{PCP}$, and the cicknss of he hin indicas the number

are highlighted on the map. This can produce interesting results, as the Pother that there could be a geographic eason for the similarities between these elements) or they could be spread out over the study area (indicating that these elements are similar in ways that don't. include a geographic factorl. These resu could suggest approaches for further analyses (for example if they suggest tha geography is not an important factor in isk) or suggest areas of focus for public

WEST NILE VIRU

Drs Kala, Atkinson and Tiwari recently used West Nile Virus (WNV) as an example of how geovisualization con be employed to simulaneously consider large amounts of data related vector-borne disease, which means it is transmitted to humans and other animals through a blood-feeding insect - in this case mosquitoes. In humans. it is often asymptomatic, though WNV can cause flu-like symptoms and, in rare cases, cause severe illnesses related to the nervous system. It was first identified in the US in 1999, and quickly spread difficult it is to predica. Because of how if is an it is to predict outbreaks of WN the use of geovisualization could provid valuable insights.

California is the most populous state in the US with historically high rates of WNV tidence. The study area was defined by WIV in $\begin{aligned} & \text { gre most similar in } \\ & \text { terms of the factors }\end{aligned}$ Geovisualization is the use of tools
contained $67 \%$ of all
reported cases. This being investigated and techniques to display large amounts is a data reduction into a cluster. $\begin{array}{lll}\text { A cluster could of data relative to geographic space. } & \begin{array}{l}\text { strategy to focus } \\ \text { on the area where }\end{array}\end{array}$ therefore contain many, but those included in a cluster are more similar to each other than to any (a) displayed in a grid of hexagons, which are shaded light to dark to show the level of dissimilarity to neighbouring clusters.

Once a SOM has been created, a parallel coordinate plot is used to consider

relative value of that factor for that specific cluster. Relationships between factors can be determined by examining the points of intersection between each line (a cluster) and each vertical axis in the graph.

Geographic mapping then displays where the elements of these clusters are on a map of the study area. When a cluster is selected all the elemists ( Cenographic data from the United States Census Bureau was then obtained for all census tracts within the study area. Census trats represent a commonly used geographic unit of analysis that represent

The demographic factors considered

in the analysis were median age, 


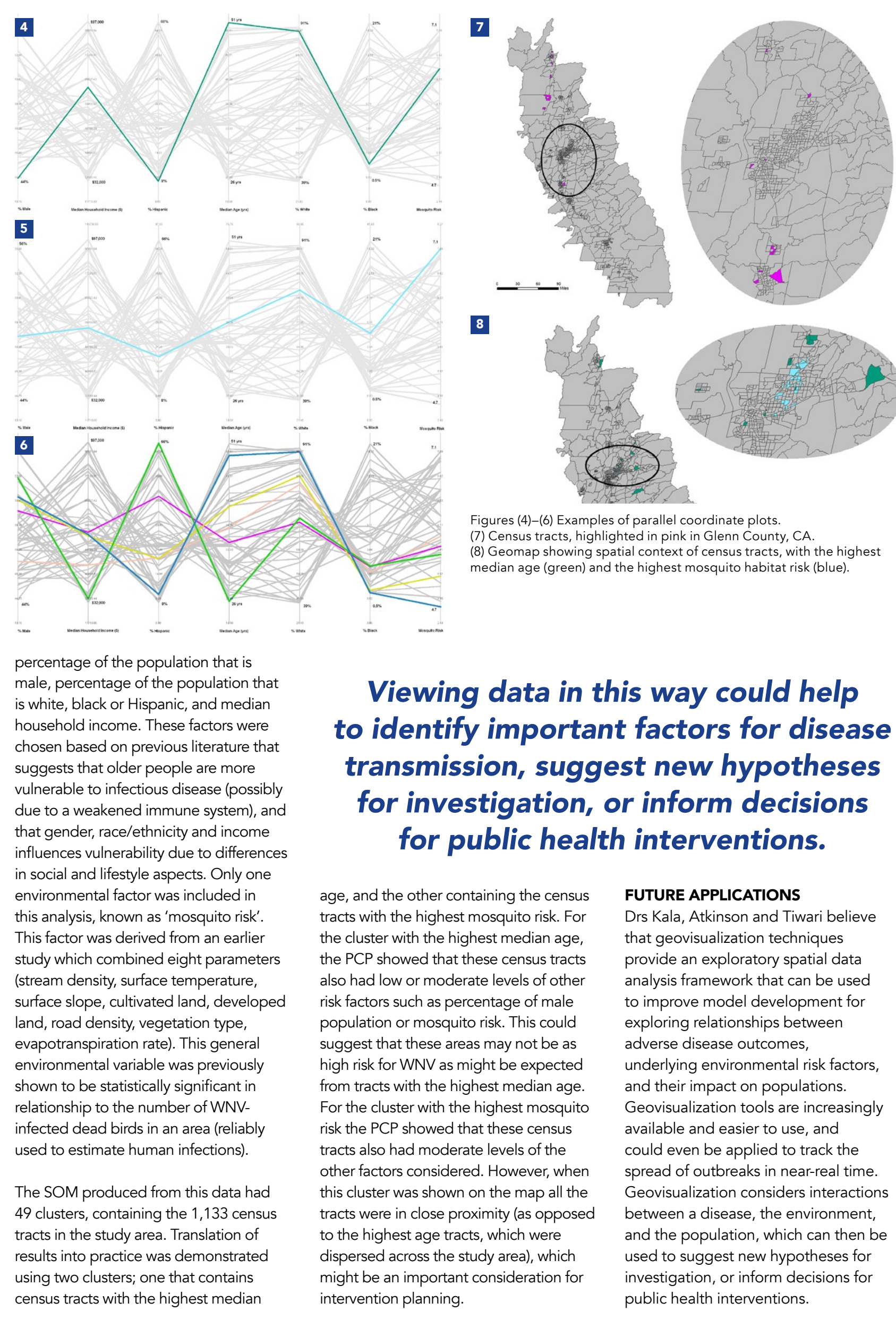

\section{Behind the Research}

(ब)

Dr Abhishek
K. Kala

E: searchkala@gmail.com

Research Objectives

Kala, Atkinson, and Tiwari use geovisualization to guide the development of analytical models to better understand,
prepare for, and react to WNV and other infectious diseases

\section{Detail}

Dr Abhishek K Kala holds a Ph.D. degree in Environmental

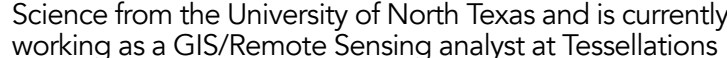
Inc. His r research focuses on developing a spatially explici source geospatial solutions to monitor environmental quality. He loves to work on his organic vegeteable garden in his spare Dr Sam Atkinson is Regents' 'Professor of Environmental
Science and Scholar in the Advanced Environmental Researt Institute at the University of North Texas. He has recently sered on the U.S. Army Science Board and is tormerV Vice Chair of the
Advisory Board.

Dr Chetan Tiwari is an Associate Professor of Geography and the Environment and is affiliated with the Advananced Environmental Research Instritute at the University of North science, response analysisis location modelling, and spatial science, responste
epideniology.

\section{Funding}

of Bibed Environmental Research Institute, Department

NTT $=$

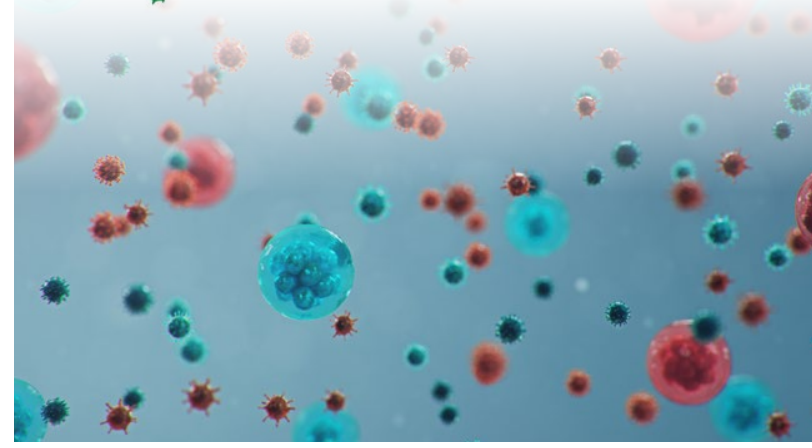
Environment (University of North Texas), U.S. Health Resources
Dr Sam Atkinson

E: atkinson@unt.edu

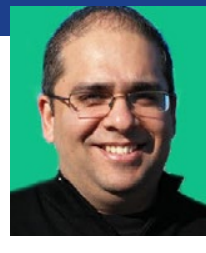

Dr Chetan

Tiwari T:+1 940-369-8103 W: https://aeri.unt.ed

\section{References}

Kala, A.K., Atkinson, S.F., \& Tiwari, C. (2020). Exploring the socioeconomic and environmental components of intectious diseases
using nultivariate geovisualization: West Nile Virus. Peer 8 :ees57 histos://doi.org/10.77177/peeri.9577

Kala, A.K., Tivari, C., Miker, A.R., \& Atkinson, S.F. (2017). A comparison of least squares regression and geographically
weighted regression modelling of West WNile virus risk based

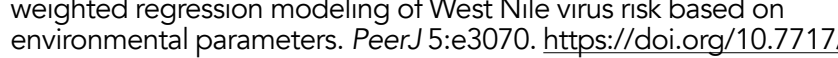

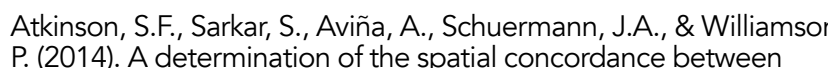
作 |xodes scapularis (black-legged tick). Geospatial Health $9(1): 203-$

Atkinson, S.F., Sarkar S, Aviña, A., Schuermann, J.A., \& Williamson,
P. (2012). Moddelling spatial concordance between Rocky Mountain spotted fever disease incidence and habitat probability of it is vector Dermacentor variabilis (American dog tick). Geosp
7(1)::11-100. https://doi.org/10.4081/gh.2012.108

Tivari, C. \& \& Rushton, G. (2010). A Spatial Analysis System for
Integrating Data, Methods and Models on Environmental Risks and Health Outcomes. Transactions in GIS 14(1): : 177-195. https:///doi. org/ Kala, A., Aktinson, S.F, \& Tivari, C. C. Posterl. Uncovering the hidden
patterns in complex epidemiological datasets. University of North exas.

\section{Personal Response}

Could geovisualization have useful applications for the current COVID-19 pandemic?

II The COVID-19 crisis is escalating, and datasets reported daily at different geographic scales include the confimed
cases total deaths total recovered, and daily count of nerver cases, total deaths, total recovered, and daily count of new
cases. Severala studies have also shown evidence that pandemic cases. Several studies have also shown evidence that pandemic
complications are more prominent in certain ethnic groups or are based on neighbourhood and demographic characteristics. There is a volume of datasets building up with several irisk tactors which makes it complicated to understand the nature of disease. Multivariate geovisualization can be of great value to help to simplify this complex data, explain interactions among findings for public heath decision making processes The can help to guide athorities for optimum planning and help minimise the disease burden. These tools can help researchers and decision makers to act in a more effective manner to
decide where survelilance should be prioritised. 